\title{
Medical sensations: experience doctoring
}

\author{
Cite as: CMAJ 2017 December 18;189:E1562-4. doi: 10.1503/cmaj.171336
}

Y ou would expect a science museum's medical exhibit to celebrate the latest technology: sophisticated imaging, three-dimensional (3-D) printing and other marvels. These are certainly part of the picture in a new medical exhibit at the renewed Canada Science and Technology Museum in Ottawa - but they aren't the focus. Surprisingly, the exhibit documents the historic growth of medical technology through the five senses: the human connection to medicine.

The idea arose after mould and a leaky roof forced the museum to shut down in 2014. The Curator of Physical Sciences and Medicine, David Pantalony, had been considering an exhibit on medical imaging, but longed to go beyond vision and explore all the senses from the medical lens, which are "foundation of medical practice." He also recalled surveys and consultations with users cautioning against forgetting the importance of human connection.

The result is "Medical Sensations," an exhibit documenting the historic growth of medical technology through the five senses. It launched Nov. 17, 2017, and will continue for several years.

The exhibit's official adviser, medical historian Shelley McKellar, said, "I worried that the art of medicine might be overlooked or downplayed, not recognizing that the meaning of the practical is often informed by the art. Implicit, but certainly present, the art of medicine emerges as a connecting exhibit theme amongst the power of the senses and the gleam of the tools." McKellar is the Hannah Chair in the History of Medicine at the Schulich School of Medicine \& Dentistry, Western University.

Pantalony hopes the exhibit becomes a platform for talking about the human dimension in medicine and the patient-

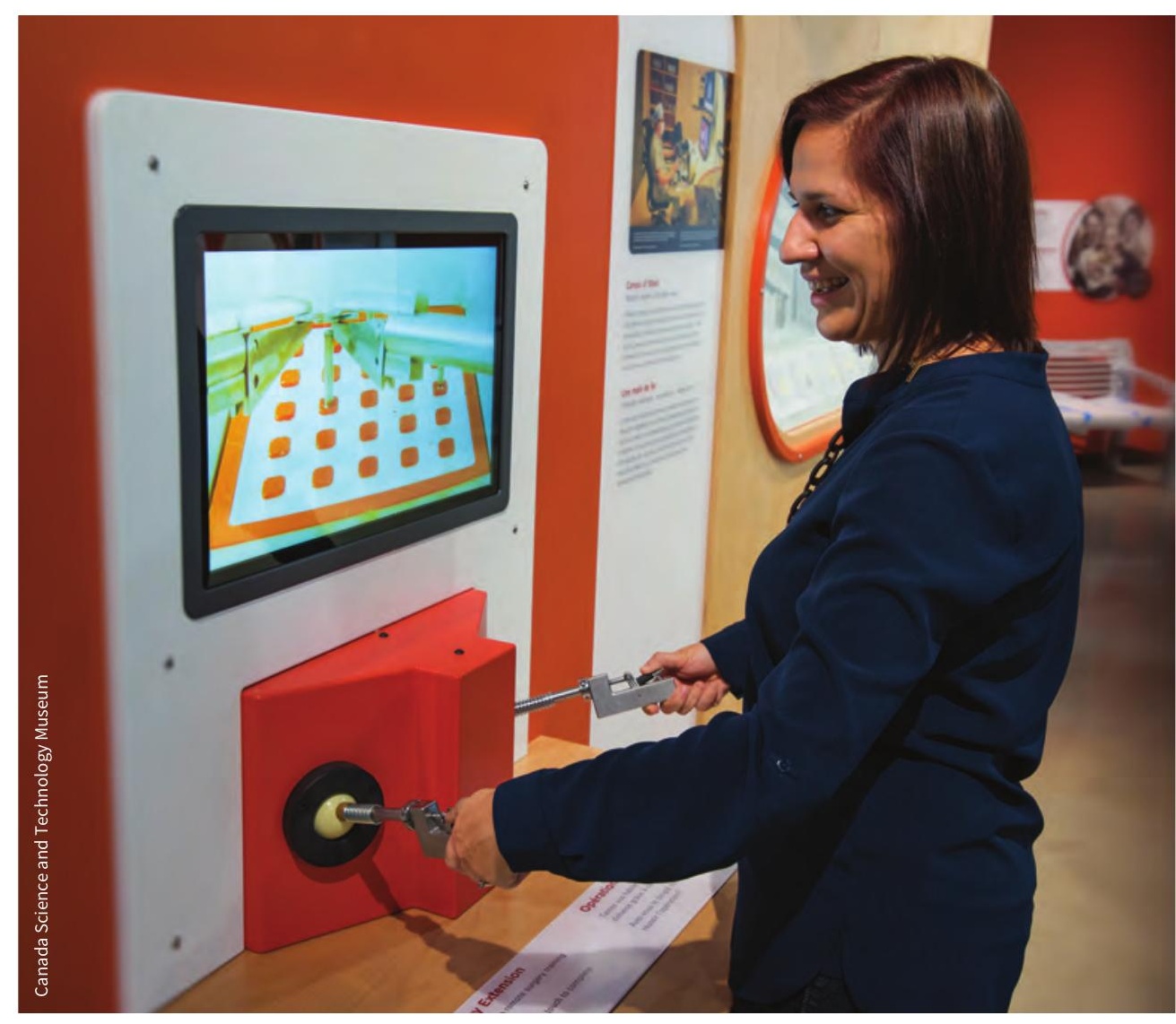

In the touch section, Annie Jacques, the exhibition and interpretation officer, tries to mimic the finesse of robotic surgery by placing large washers on pins - an exercise that is frankly humbling.

doctor relationship. This is depicted by artifacts, such as the iconic doctor's bag, which represents a time when physicians routinely made home visits.

"Medical Sensations," which occupies 3500 square feet of the 80000 square-foot museum, features nearly 100 pieces, mostly from the museum's extensive medical collection of about 8000 pieces, many of which are from the former Academy of Medicine Collection.

It is one of the first full-scale medical exhibits in a North American science museum. Others have focused on specific aspects, such as a 2009 Ottawa exhibit that examined the origins of the green colour used in medical apparatus and clothing. ${ }^{1}$

The largest section of this new exhibit concentrates on sound, including stethoscopes. It begins with a reproduction of the first one, the tube monoaural, invented in 1815 by René Laennec, and used by Sir William Osler, the renowned Canadian physician and teacher of modern medicine. It was handcrafted by Montreal cardiovascular surgeon $\mathrm{Dr}$. Harold Segall.

The stethoscope enabled physicians to listen more acutely to the inside of the 
body, but it also had a social dimension: it created a physical distance between the doctor and patient. Some saw this as a positive step that might, for example, put female patients more at ease. Others opposed it as unnecessary. Representing today's technology is a 3-D printed stethoscope that cost about 80 cents, but is as powerful as a $\$ 150$ instrument.

The stethoscope engendered a huge vocabulary of sounds that doctors learned to listen for. On the flip side of the stethoscope display, visitors can hear different heartbeats; elsewhere, they can listen to coughs: whooping, croup, dry and wet.

An adjacent panel depicts Dr. Lisa Monkman, an Indigenous family physician in Dauphin, Manitoba, who is quoted about the need to listen to patient's histories as a "holistic way of looking at personal health and well-being, incorporating your emotional, spiritual, mental and physical health."

Taste and smell are scantily, although intriguingly, depicted through an image of a urine wheel from 1506, a surprisingly sophisticated tool for diagnosing ailments based on the colour, smell and sometimes the taste of urine. The classic taste-disease connection for centuries

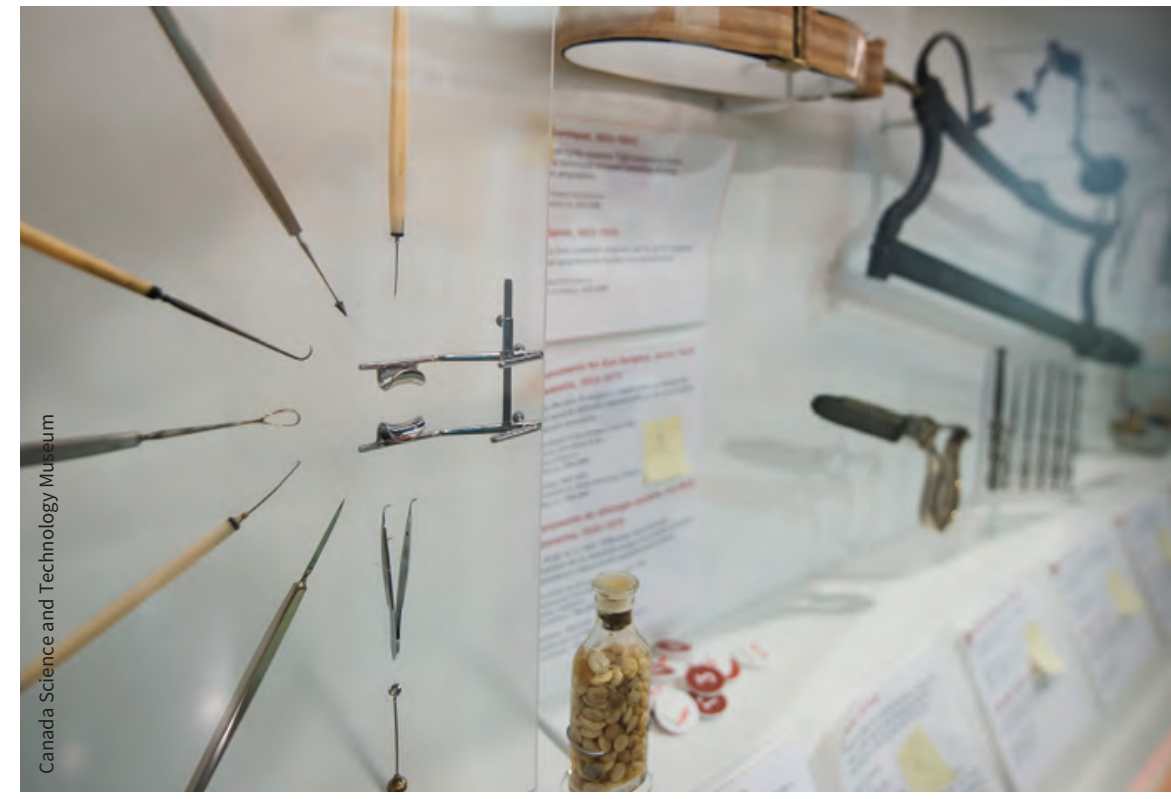

Curator David Pantalony's favourite artifacts are these 17th century eye surgery instruments: "They are so refined and delicate and sophisticated for that time; there's something very powerful about those as an artifact." They are accompanied by a specimen bottle of cataracts.

was sweet-tasting urine and diabetes. "There's that ick factor for the public," said Pantalony.

The more extensive touch section showcases historic surgical instruments and a specimen bottle containing the first appendix removed in Canada on May 10, 1883, by Dr. Abraham Groves, near Fer- gus, Ont. The patient recovered. Dr. Maude Abbott, a world-famous expert on congenital heart disease at McGill University, is honoured in this section for teaching students to distinguish features in anatomy and pathology.

An anatomic model of the body, originally used by Dr. Yankoff in his east-end

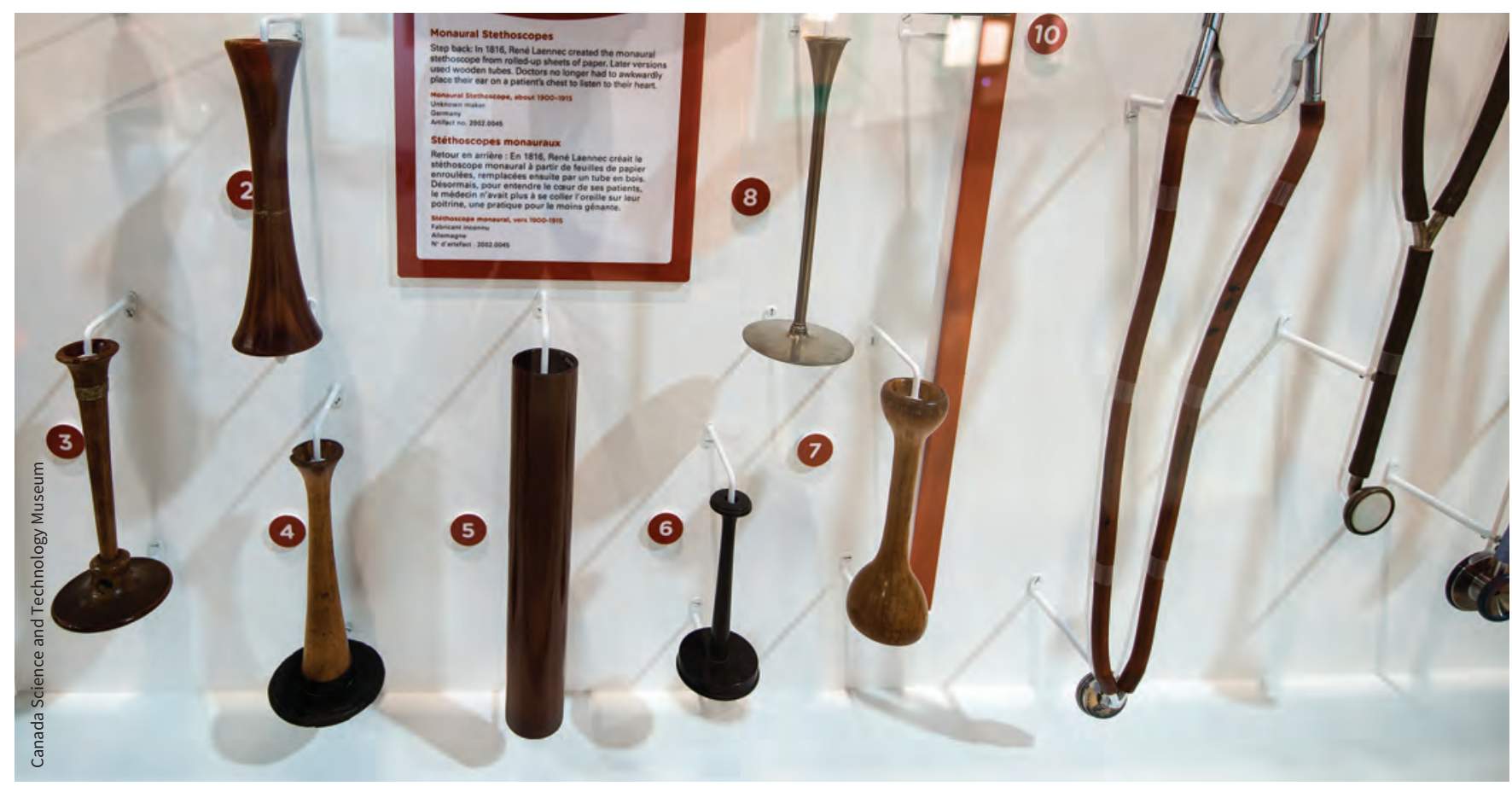

The older stethoscopes were collected by physicians in the 1920s and 1930s, when the profession was undergoing massive changes, such as the introduction of the $x$-ray; the physicians were nostalgic for the earlier technologies and what they represented. 
Toronto practice, particularly when treating non-English-speaking patients, is "exploded" to show its 500 parts fully.

Seeing is depicted through old and new technology ranging from moulages (wax molds) of skin diseases, a specimen of a tumour in the brain and magnetic resonance imaging (MRI). At a touch, the "Visible Body" app brings up MRI views ranging from body systems to crosssections. And with the "Inside the Body
Interactive" app, skeletal, nervous and muscular systems mirror the insides of visitors as they move in front of a giant screen. Dancing is encouraged.

Bringing it all together is an iconic doctor's bag that belonged to Dr. Walter Woodrow, Orillia's legendary flying doctor who visited patients on his bush plane. Pantalony recalls showing visual aspects to focus groups. "One person said 'look how far we've come,' referring to an MRI, and

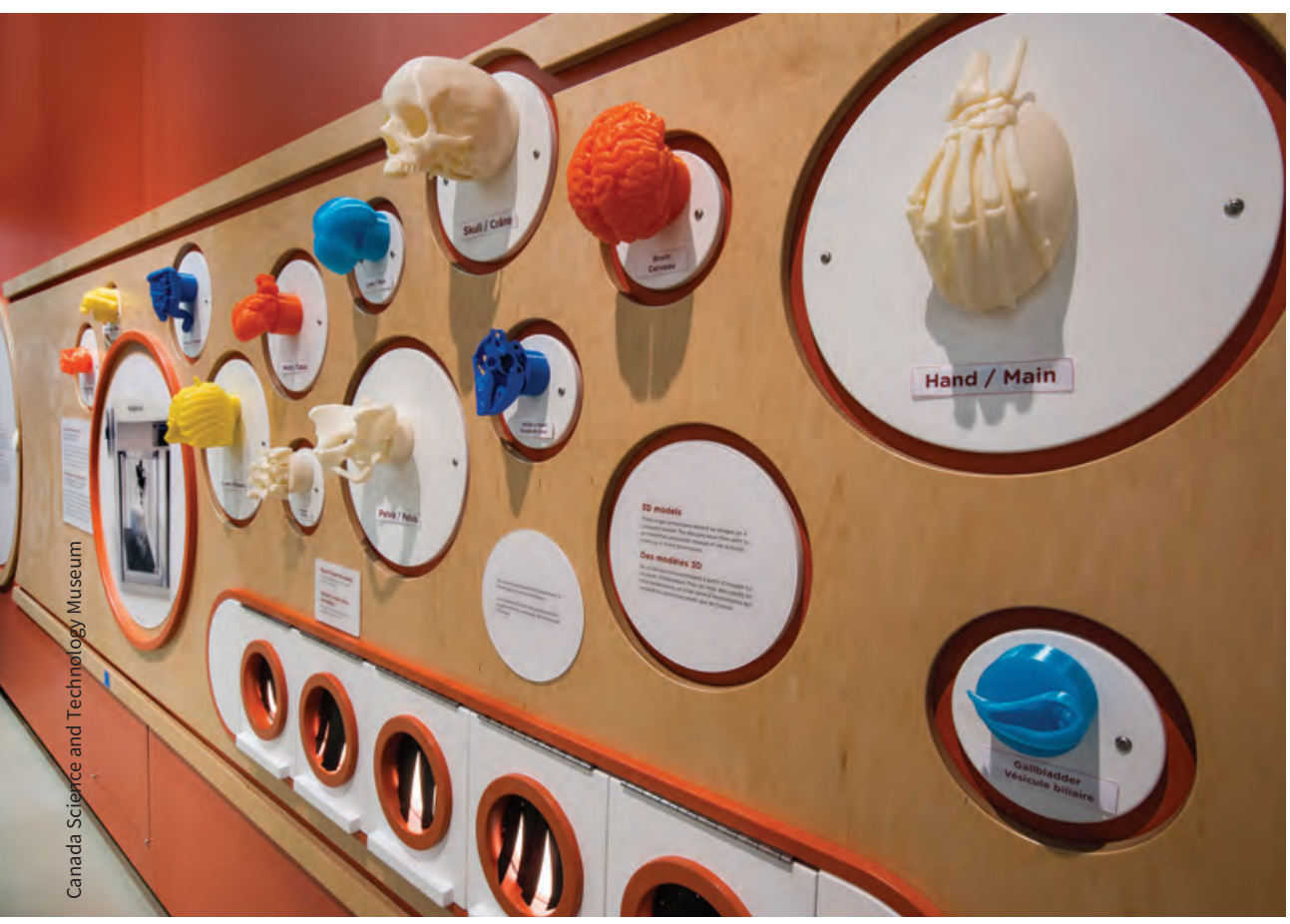

The Ottawa Hospital's medical imaging teams produced 15 three-dimensional printed organs used for diagnosis, surgery planning and patient communication. Visitors can put their hands in covered holes (bottom) and play guess-the-organ. someone else said, 'but look how much we've lost: the doctor used to come to our house.' That's why we have the doctor's bag - what we've gained, what we've lost."

The bag's contents come from multiple sources. Dr. Thomas Morley, a well-known neurosurgeon, provides cloves - an olfactory diagnostic. There is also a vial of early insulin and one of the first clinical thermometers from the 19th century.

Notably absent are the patients themselves, although Pantalony said a future exhibit may focus on them. Nurses and other health care providers, essential to the provision of humane medicine, are also notably absent. The focus is primarily on the provision of medicine by Western physicians. To be fair, the breadth of the topic necessitated imposing limits, and the exhibit is nonetheless fascinating both in focus and content.

The exhibit is best summed up in the words of Dr. William Osler, who bridged historic to modern medicine and taught students to observe carefully. "Use your five senses; the art of the practice of medicine is to be learned only by experience. Learn to see, learn to hear, learn to feel, learn to smell, and know that by practice alone can you become expert."

\section{Barbara Sibbald BJ}

CMAJ

\section{Reference}

1. Pantalony D. The colour of medicine. CMAJ 2009;181:402-3. 